\title{
Behavior of Waste Printed Circuit Board (WPCB) Materials in the Copper Matte Smelting Process
}

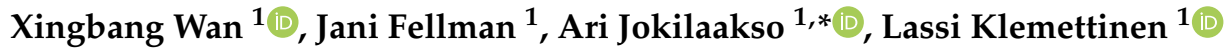 \\ and Miikka Marjakoski ${ }^{2}$ \\ 1 Department of Chemical and Metallurgical Engineering, School of Chemical Engineering, Aalto University, \\ P.O. Box 16100, 00076 Aalto, Finland; xingbang.wan@aalto.fi (X.W.); jani.fellman@aalto.fi (J.F.); \\ lassi.klemettinen@aalto.fi (L.K.) \\ 2 Boliden Harjavalta, Teollisuuskatu 1, 29200 Harjavalta, Finland; miikka.marjakoski@boliden.com \\ * Correspondence: ari.jokilaakso@aalto.fi; Tel.: +358-50-313-8885
}

Received: 28 September 2018; Accepted: 29 October 2018; Published: 31 October 2018

\begin{abstract}
The amount of waste electrical and electronic equipment (WEEE) in the world has grown rapidly during recent decades, and with the depletion of primary ores, there is urgent need for industries to study new sources for metals. Waste printed circuit boards (WPCB) are a part of WEEE, which have a higher concentration of copper and precious metals when compared to primary ore sources. PCB materials can be processed using pyrometallurgical routes, and some industrial processes, such as copper flash smelting, have utilized this type of waste in limited amounts for years. For the purpose of recycling these materials through smelting processes, this work studied the behavior of WPCB scrap when dropped on top of molten slag. A series of experiments was carried out during this research at a temperature of $1350^{\circ} \mathrm{C}$, in an inert atmosphere with different melting times. The time required for complete melting of the PCB pieces was 2-5 min, after which molten alloy droplets containing $\mathrm{Cu}, \mathrm{Pb}, \mathrm{Sn}, \mathrm{Ni}, \mathrm{Au}$, and $\mathrm{Ag}$ formed and started descending toward the bottom of the crucible. The ceramic fraction of the PCB material mixed with slag and the polymer fraction was pyrolyzed during the high-temperature experiments. The results give an understanding of PCB melting behavior and their use as a part of the smelting furnace feed mixture. However, more research is needed to fully understand how the different elements affect the process as the amount of PCB in the feed increases. The physical behavior and distribution of PCB materials in fayalite slag during the smelting process are outlined, and the results of this work form a basis for future studies about the chemical reaction behavior and kinetics when PCB materials are introduced into the copper smelting process.
\end{abstract}

Keywords: WPCB; melting behavior; flash smelting

\section{Introduction}

Recent advancements in electronic and electrical technologies have caused rapid growth in the amount of waste electrical and electronic equipment (WEEE) in the last two decades. This is largely credited to global trends in the number of users, technological advances, efficiency, as well as social and economic development. Additionally, the increase in average disposable income has reduced the cycle times of electronic equipment. Globally generated e-waste amounted to 44.7 million metric tons in 2016 [1]. The amount of collected e-waste is expected to surge rapidly, which would further increase the need for efficient recycling solutions. The plentiful amount of precious metals (PMs) in WEEE are especially becoming of greater importance and focus [2]. In today's circular economy, an essential challenge is how to incorporate the rising amount of WEEE into existing industrial processes as a secondary feed material with additional value $[3,4]$. 
With the continuous growth of demand for metals, and parallel degradation and depletion of primary ores, there is an increasing need for secondary raw materials. Some studies have been conducted regarding the behavior and recovery possibilities of different metals in WPCBs with different kinds of metallurgical processes, such as leaching in different media $[5,6]$. During the last decade, the practice of using WPCB as a feed material in copper smelting has also become a focus of research and development. WPCBs' high PM content has incensed commercial smelter operators toward developing existing processes for accepting WEEE and WPCB. Their use has already been implemented in several integrated processes around the world, such as the Umicore Hoboken plant in Belgium [7] or the Boliden plant in Sweden [8]. In Japan and Korea, the Mitsubishi smelting process has been developed for adapting WEEE as a secondary material source [9]. A few commercial smelting operations have moved towards charging WEEE into a copper flash-smelting furnace (FSF) as an added material; one example is the Horne smelter in Canada [10]. This process differs from direct reduction metal-slag systems, as the flash furnace maintains a matte-slag environment. It also has variances to other matte-slag systems, as WEEE material is charged together with the primary copper concentrate.

Experimental investigations on the thermodynamic properties and distributions of minor (WEEE) elements in different oxygen partial pressures have been carried out recently by several researchers, mostly for metal-slag systems [11-18] but also in matte-slag equilibria [19]. Some model predictions for PCB's minor element distributions, including $\mathrm{Pb}, \mathrm{Sn}, \mathrm{Ni}$ and $\mathrm{Zn}$, have also been proposed [20]. The decomposition and oxidation rates of concentrate material in the FSF reaction shaft have been extensively studied by several researchers [21-27], and some modeling works using fluid dynamic software were finished based on these results.

However, the distribution and kinetic behavior of WEEE/WPCB in the flash-smelting process still lack investigation. More research is needed to evaluate the compatibility of WPCB with traditional FS processes, regarding the capacity of simultaneous smelting of WPCB and copper concentrate.

This research work expands the work done previously [28], which studied the matte-slag reaction system. The aim of this research is to find out the behavior and distribution of WPCB scrap in the slag phase when injected on top of the slag from the roof of a settler where the flight time is short and atmosphere is no longer oxidizing.

\section{Materials and Methods}

\subsection{Materials}

The WPCB pieces (shown in Figure 1a) were cut from a disassembled mobile-phone motherboard. The size of the pieces was approximately $5 \mathrm{~mm} \times 5 \mathrm{~mm} \times 1 \mathrm{~mm}$. The comparison samples, referred to as "synthetic PCB" (Figure 1b) were comprised of copper-nickel alloy (Alfa Aesar, Karlsruhe, Germany, $0.51 \mathrm{~mm}$ thick, 33\% copper and $67 \%$ nickel) pieces wrapped in aluminum foil (Fisher Scientific, Pittsburgh, PA, USA, $24 \mu \mathrm{m}$ thick). The size of these comparison pieces was $5 \mathrm{~mm} \times 5 \mathrm{~mm}$ $\times 1 \mathrm{~mm}$ as well.

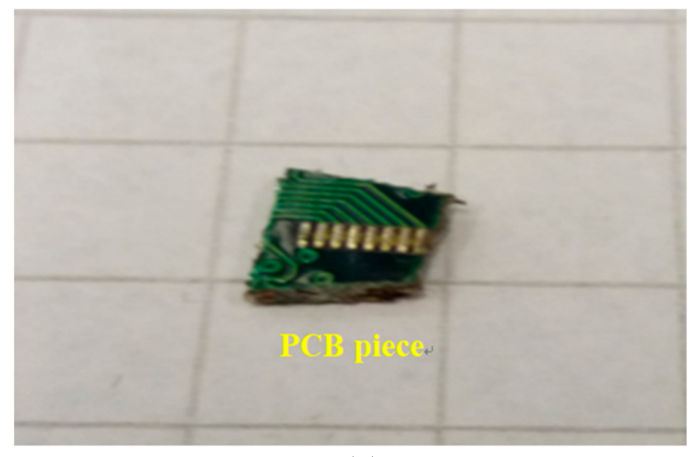

(a)

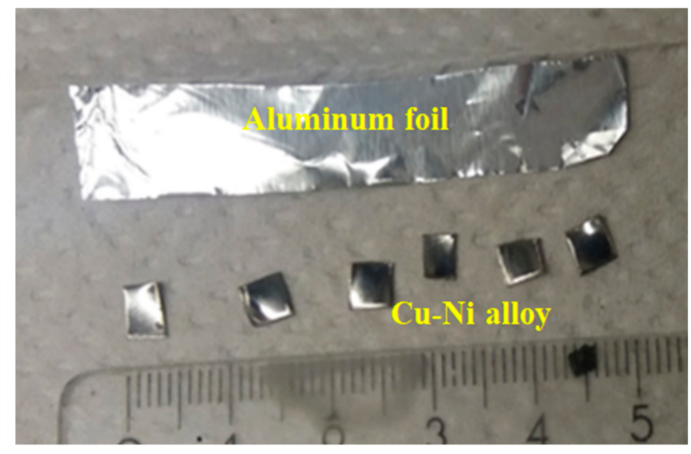

(b)

Figure 1. Materials utilized in this study: (a) printed circuit-board (PCB) piece; (b) synthetic PCB pieces. 
The synthetic slag was a mixture of hematite (Alfa Aesar, Kandel, Germany, 99.998\% purity), silica (Umicore, Balzers, Liechtenstein, 99.99\% purity), and metallic iron (Alfa Aesar, Kandel, Germany, $99.5 \%$ purity), with mass ratios of $50 \% \mathrm{Fe}_{2} \mathrm{O}_{3}, 30 \% \mathrm{SiO}_{2}$, and $20 \% \mathrm{Fe}$. The amount of slag used for each experiment was $1.0 \mathrm{~g}$. The slag-powder mixture was placed into a silica crucible and introduced into the furnace.

\subsection{Apparatus}

The experimental apparatus used in this research is shown in Figure 2. It is comprised of a vertical tube furnace (Lenton LTF 16/-/450, Lenton, Nottingham, UK) which is equipped with 4 silicon carbide (SiC) heating elements and a Eurotherm PID temperature controller (Eurotherm, Ashburn, VA, USA). The furnace working tube is made of impervious pure alumina (Frialit AL 23; Friatec AG, Germany) with $45 / 38 \mathrm{~mm}$ OD/ID. On top of the working tube, a lid equipped with the water-cooling system has three small holes. From the first hole, an S-type Pt/Pt-10Rh thermocouple (Johnson-Matthey Noble Metals, London, UK) inside a protective alumina tube was inserted into the furnace. The output voltage of the thermocouple was measured with a Keithley 2000DMM multimeter (Keithley, Solon, $\mathrm{OH}, \mathrm{USA}$ ). A Pt100 resistant thermometer (SKS-Group, Vantaa, Finland) was connected to a Keithley 2010DMM multimeter for performing cold-junction compensation. Temperature data were logged with LabVIEW software (National Instruments, Austin, TX, USA). From the second hole, a platinum wire (inside a $22 \mathrm{~mm}$ alumina guiding tube, see Figure 2) was inserted for raising the sample to the reaction zone of the furnace. The third hole was equipped with a re-sealable rubber cork for dropping the PCB pieces into the alumina guiding tube and eventually into the silica crucible containing the molten slag.

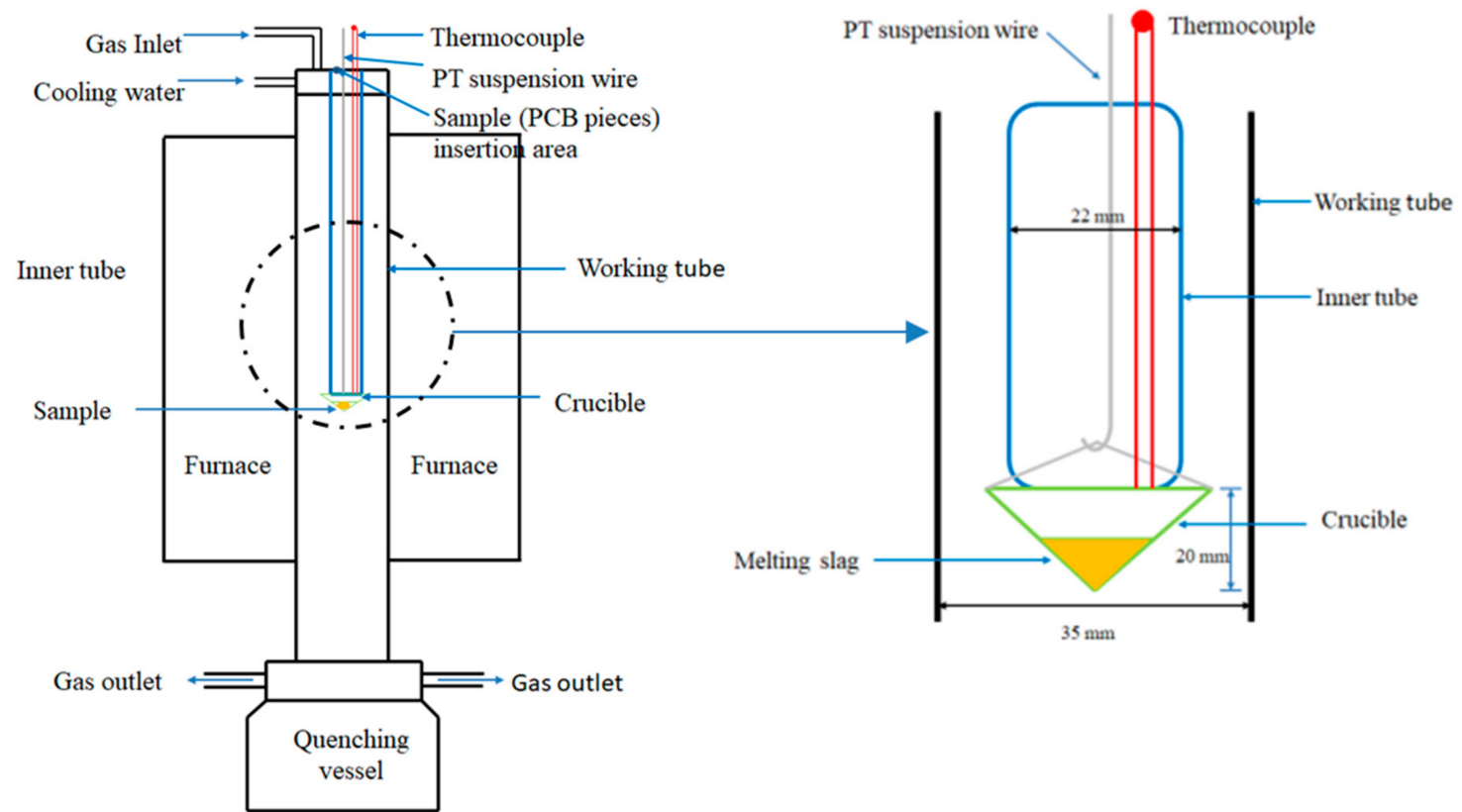

Figure 2. A schematic of the experimental furnace and details of the hot zone. During quenching of the sample, the quenching vessel was lifted to cover the bottom end of the furnace work tube for preserving the inert-gas atmosphere.

\subsection{Procedure}

Before the experiments, the temperature inside the working tube of the furnace was measured, the area with the highest temperature was defined as the hot zone, and its temperature was set to $1350{ }^{\circ} \mathrm{C}$. The temperature was kept constant throughout the experiments. After introducing the crucible-sample-platinum basket assembly into the cold zone of the furnace and sealing the lower end 
of the furnace work tube, an argon (Aga Linde, Espoo, Finland, 99.999\% purity) gas flow was turned on and given 10 min to fill the tube to exclude oxygen. Then, the crucible with the slag was lifted up to the hot zone with the Pt suspension wire, where it was kept for 5 min for the slag to melt. After this, a piece of WPCB was dropped into the crucible from the top of the furnace through a small resealable hole. The melting time was measured from the moment the piece was dropped through the hole to the moment the sample was quenched in $0{ }^{\circ} \mathrm{C}$ ice water in the quenching vessel.

Two different experimental series were conducted. In the first series, actual PCB pieces were used, and the melting times were 25,60, 120, and $300 \mathrm{~s}$. Each time interval experiment was repeated at least twice to ensure reliable results. In the second series, the behavior of synthetic PCB (copper-nickel alloy wrapped in aluminum foil) pieces was studied with the same procedure.

The quenched samples in their cone-shaped crucibles were mounted in epoxy resin and then cut in half from a location that seemed to contain PCB material in visual inspection. The obtained semicircle-shaped pieces were ground and polished using traditional dry metallographic techniques. Sufficient conductivity on the surface was ensured with a carbon coating (Leica EM SCD050, Leica Microsystems, Wetzlar, Germany). The samples were analyzed with a Tescan MIRA 3 Scanning Electron Microscope (SEM, Tescan, Brno, Czech Republic) equipped with an UltraDry Silicon Drift Energy Dispersive X-Ray Spectrometer and NSS Microanalysis Software (EDS, Thermo Fisher Scientific, Waltham, MA, USA). The acceleration voltage and beam current of the SEM were $15 \mathrm{kV}$ and $10 \mathrm{nA}$, respectively. The external standard materials used for elemental analysis were olivine $(\mathrm{O})$, hematite (Fe), quartz (Si), and pure metals for $\mathrm{Cu}, \mathrm{Pb}, \mathrm{Sn}, \mathrm{Ni}, \mathrm{Au}, \mathrm{Ag}$, and PGMs.

\section{Results and Discussion}

The experiments were conducted in an inert argon atmosphere for verifying the behavior of the unreacted WPCB material in the settler area without free oxygen. During the introduction of the PCB sample pieces into the furnace, tiny amounts of oxygen may have entered the furnace, but the effect of this was considered negligible. The synthetic PCB material was selected for investigating the melting and settling behavior of only the metallic PCB fraction.

\subsection{Basic Matte-Slag Reaction during the Flash-Smelting Process}

During the flash-smelting process, most of the concentrate particles react with oxygen and become molten due to exothermic reactions. The slag phase forms and separates from the matte phase in the settler area through the following reactions, and, during the processes described in Equations (1)-(4), iron sulfide is continuously removed from the matte phase, the copper content in the matte phase increases, and more slag appears.

$$
\begin{gathered}
3 \mathrm{Fe}_{3} \mathrm{O}_{4}(\mathrm{~s})+\mathrm{FeS}_{(\text {matte })}=10 \mathrm{FeO}_{(\text {slag })}+\mathrm{SO}_{2}(\mathrm{~g}) \\
\mathrm{Cu}_{2} \mathrm{~S}(\mathrm{l})+\mathrm{O}_{2}(\mathrm{~g})=2 \mathrm{Cu}_{(\text {metal })}+\mathrm{SO}_{2}(\mathrm{~g}) \\
2 \mathrm{Fe}_{2} \mathrm{O}_{3}+\mathrm{S}_{(\text {matte })}=4 \mathrm{FeO}_{(\text {slag })}+\mathrm{SO}_{2}(\mathrm{~g}) \\
3 \mathrm{Fe}_{3} \mathrm{O}_{4}(\mathrm{~s})+\mathrm{FeS}_{(\text {matte })}+5 \mathrm{SiO}_{2}=5 \mathrm{Fe}_{2} \mathrm{SiO}_{4(\text { slag })}+\mathrm{SO}_{2}(\mathrm{~g})
\end{gathered}
$$

However, during the industrial process, some particles do not react completely and fall to the settler area as partly or fully unreacted. Kim and Themelis [29], Jokilaakso et al. and Ahokainen and Jokilaakso $[23,30]$ found out how larger particles fragment into small ones in the reaction shaft, and the result showed that unreacted particles cannot be ignored. In that case, the decomposition of these particles may start in the settler, where oxygen pressure is low.

The same phenomenon may happen when adding WPCB material into the concentrate during the flash-smelting process, and pieces of WPCB can directly drop into the settler and melt only in the slag phase. In addition, WPCB scrap can be directly added into the settler from the roof of the settler area. 
In order to investigate the melting behavior of the WPCB in the slag phase, two series of experiments were done in this study to investigate the physical behavior of the WPCB in the fayalite slag.

\subsection{Behavior of WPCB Samples in the Slag Phase}

Figure 3a-d shows SEM micrographs of the samples and the structure change of the WPCB pieces as a function of time in argon atmosphere. From the overview of the $25 \mathrm{~s}$ WPCB sample, a visible WPCB structure on the top of molten slag can be clearly observed, so it can be concluded that $25 \mathrm{~s}$ of contacting time is far too short to melt the whole WPCB sample. With the contacting time of $60 \mathrm{~s}$, the WPCB piece has disintegrated to some extent, and the droplets found in this sample are primarily copper mixed with minor trace metals such as nickel, lead and tin. However, $60 \mathrm{~s}$ is not enough to allow the copper alloy droplets to settle through the slag layer towards the bottom.

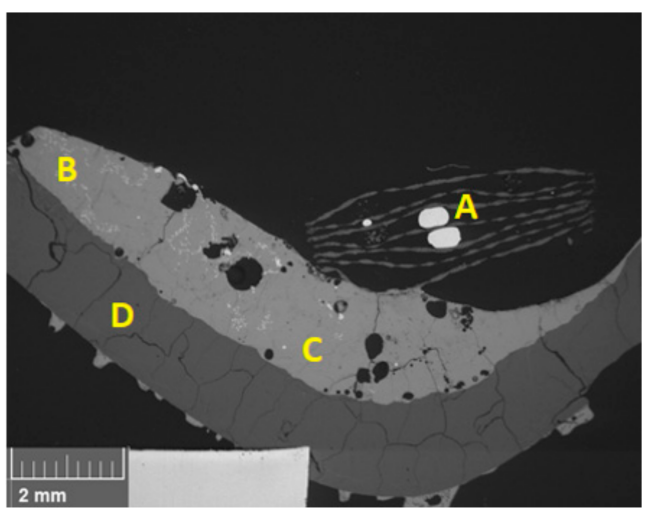

(a) $t=25 \mathrm{~s}$

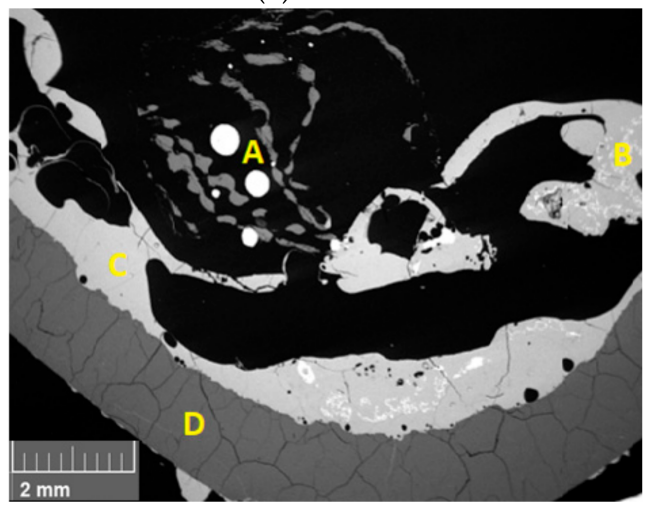

(c) $t=120 \mathrm{~s}$

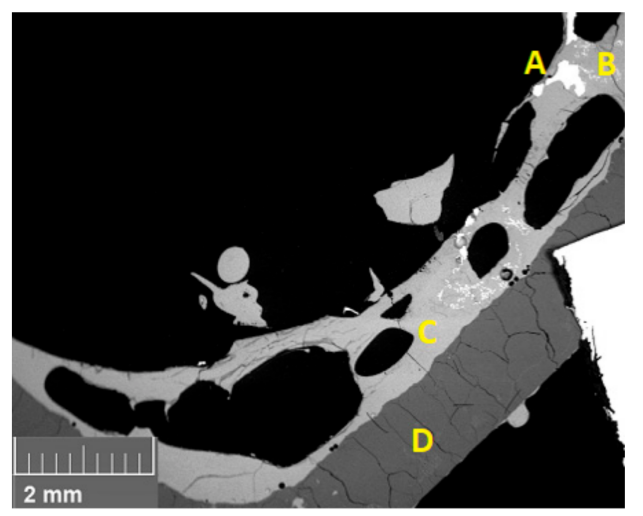

(b) $t=60 \mathrm{~s}$

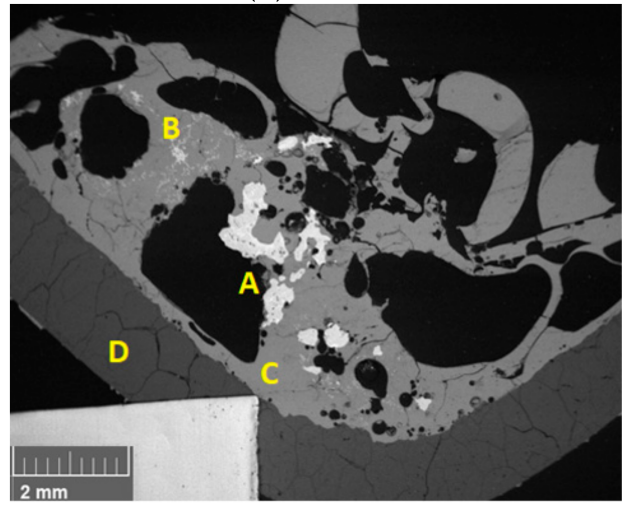

(d) $t=300 \mathrm{~s}$

Figure 3. Scanning electron microscope (SEM)—backscattered electron (BSE) micrographs of the waste PCB (WPCB) specimens at different melting times. The letters indicate (a) metal droplets from PCB, (b) unreacted iron from the slag mixture, (c) liquid slag, and (d) silica crucible.

After $120 \mathrm{~s}$ of melting, shown in Figure 3c, a remainder of the WPCB structure with copper droplets could be found above the slag, and there were also multiple metal droplets inside the slag, which meant the melting and settling process was not finished. Since the plastic and ceramic structure of the WPCB was still visible after $120 \mathrm{~s}$, it was most probably present in the $60 \mathrm{~s}$ sample as well; however, this cross-section in Figure $3 \mathrm{~b}$ does not show it. Figure $3 \mathrm{~d}$ shows an overview of the $300 \mathrm{~s}$ sample, where the WPCB structure has already melted entirely, and the small metal droplets coalesced into bigger-size droplets. At that time, the melting process of the PCB was finished, but the settling process of the metal droplets toward the bottom of the silica crucible was still ongoing.

Due to the short time allowed for the slag mixture to melt before introducing the WPCB samples, some metallic iron is found from the slag (indicated with B in Figures $3 a-d$ and $5 a-d$ ). This indicates that the slag was still far from equilibrium. The aim of this study was to investigate the behavior 
of the WPCB pieces in a molten-slag bath, and therefore the state of the slag was not of great importance, as long as it was molten. When the melting time of the slag-powder mixture was prolonged, a considerable amount of slag dripped through the crucible (visible in Figure 3a), reducing the volume of the slag inside the crucible. If the slag volume were too low, i.e., only a slag "film" remained on the surface of the crucible, observations about the settling behavior of the metal droplets originating from the PCB pieces could not be made.

For some of the metal droplets, SEM-EDS analysis areas are shown in Figure $4 \mathrm{a}-\mathrm{d}$. The compositions (in $\mathrm{w} \mathrm{t} \%$ ) of analysis areas $1-8$ in Figure $4 \mathrm{a}-\mathrm{d}$ are listed in Table 1.

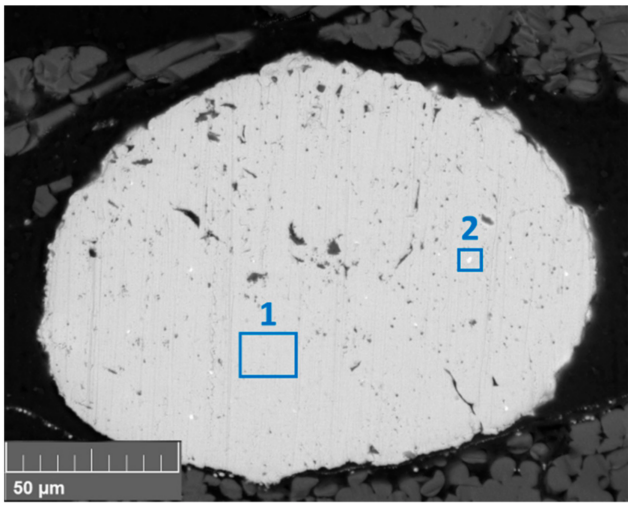

(a) $t=25 \mathrm{~s}$

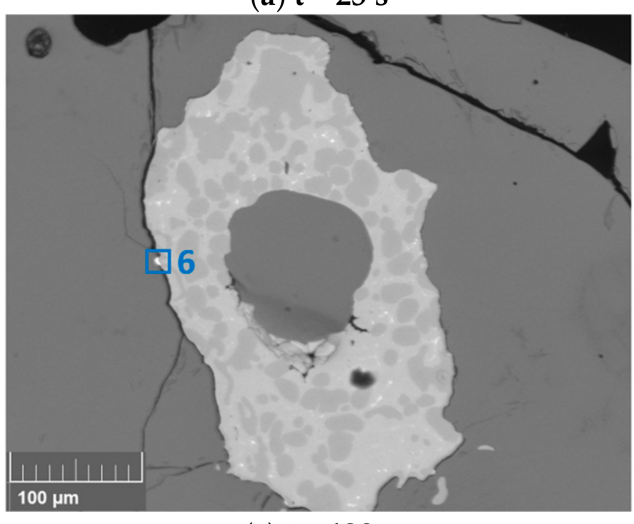

(c) $t=120 \mathrm{~s}$

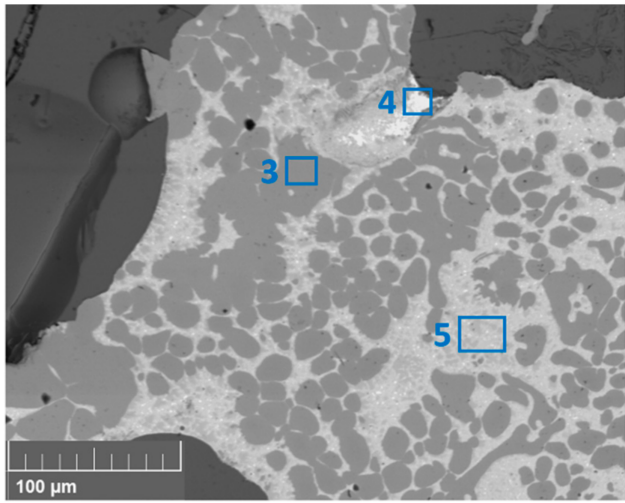

(b) $t=60 \mathrm{~s}$

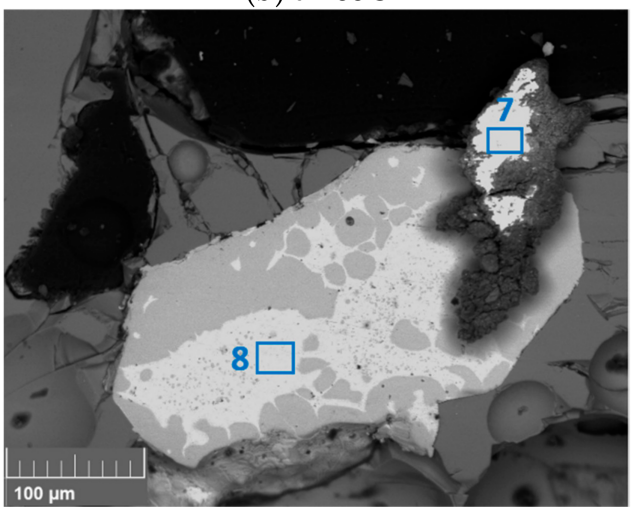

(d) $t=300 \mathrm{~s}$

Figure 4. SEM-EDS analysis areas of metal droplets originating from PCB pieces. 1: $\mathrm{Cu}, 2$ : $\mathrm{Cu}-\mathrm{Ni}$ alloy, 3: $\mathrm{Fe}, 4$ : $\mathrm{Cu}-\mathrm{Pb}-\mathrm{Sn}$ alloy, 5: Cu-Sn alloy, 6: $\mathrm{Cu}-\mathrm{Fe}-\mathrm{Pb}$ alloy, 7: $\mathrm{Pb}, 8: \mathrm{Cu}-\mathrm{Fe}$ alloy.

The metal-alloy droplets, originating from the WPCB pieces, had different compositions and could be roughly divided into $\mathrm{Cu}$-rich and Fe-rich alloys. According to the SEM-EDS results, these droplets contained copper, nickel, lead, tin, and minor traces of gold, silver, and platinum group metals. Different alloy compositions are commonly found from the same large droplets, as shown in Figure $4 \mathrm{~b}-\mathrm{d}$. In was observed that $\mathrm{Cu}$-rich areas were more likely to contain valuable and precious metals than Fe-rich areas.

Table 1. EDS analysis results (in $w \mathrm{t} \%$ ) of the metal droplets shown in Figure $4 \mathrm{a}-\mathrm{d}$.

\begin{tabular}{cccccccc}
\hline Area & $\mathbf{C u}$ & $\mathbf{F e}$ & $\mathbf{N i}$ & $\mathbf{P b}$ & $\mathbf{S n}$ & $\mathbf{A g}$ & $\mathbf{A u}$ \\
\hline 1 & 95.7 & $<0.1$ & 0.23 & 0.8 & 0.1 & 0.1 & 0 \\
2 & 90.9 & $<0.1$ & 8.1 & 0.1 & 0 & 0 & 0 \\
3 & 0 & 95.7 & 0 & 0 & 0 & 0 & 0 \\
4 & 42.1 & 0 & 0 & 37.3 & 16.0 & 0 & 0 \\
5 & 80.9 & 0 & 0 & 0 & 20.5 & 0.8 & 0 \\
6 & 33.2 & 32.8 & 0 & 4.3 & 0 & 0 & 0 \\
7 & 2.3 & 0 & 0 & 85.4 & 0 & 0 & $<0.1$ \\
8 & 44.4 & 57.6 & 0 & 0 & 0 & 0.4 & 0 \\
\hline
\end{tabular}


When observing the WPCB sample results, the melting of the WPCB structure started at the outer copper layers and moved toward the center of the sample. The WPCB pieces were found to gradually melt in 2-5 min. After $5 \mathrm{~min}$, WPCB structure seemed to be completely molten and broken down. When comparing this time to the theoretical results using a lumped capacitance method [31] for calculating melting time, the experimentally observed melting time of around 5 min seemed appropriate.

\subsection{Behavior of Synthetic PCB Samples in the Slag Phase}

Figure 5a-d shows micrographs of the synthetic PCB samples. After $25 \mathrm{~s}$, the synthetic sample remained on top of the molten slag and melted more thoroughly than the WPCB sample at the same time. The large metal-alloy droplet already started to mix into the slag phase. After longer contacting times, from 60 to $300 \mathrm{~s}$, basically no further changes took place, but the molten and almost undivided metal droplets settled through the slag without considerable mixing into the slag or disintegration. Without the ceramic and plastic fraction of the WPCB samples, the synthetic PCB melted much faster, and remained as one metal lump settling through the slag. In the WPCB samples, the metallic fractions were scattered throughout the plastic-ceramic support structure of the circuit board, and therefore a larger metal droplet most likely formed only when all the individual droplets settled through the slag layer to the bottom of the crucible.

During the WPCB melting, the complex material layers and their different properties made the melting process very non-uniform. Copper layers and lead-tin solders melt almost instantaneously, while ceramic structures and plastic parts take more time to melt, which increases the total melting time.

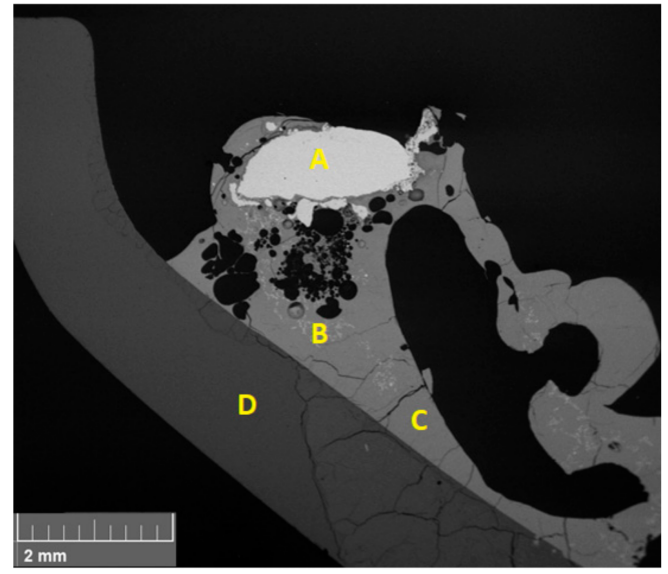

(a) $t=25 \mathrm{~s}$

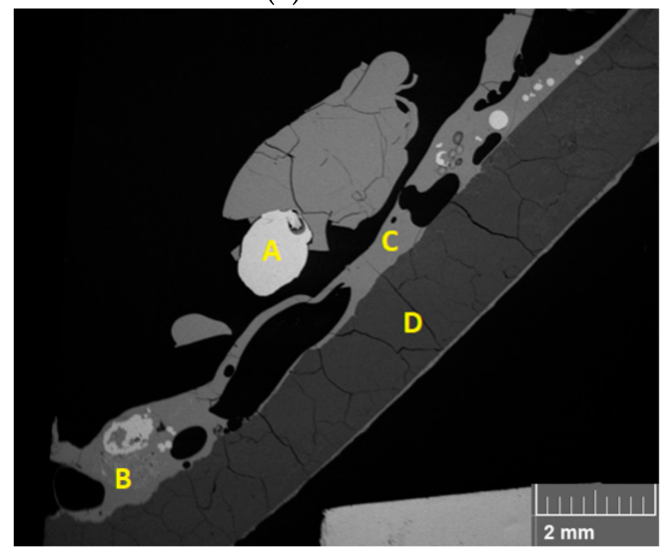

(c) $t=120 \mathrm{~s}$

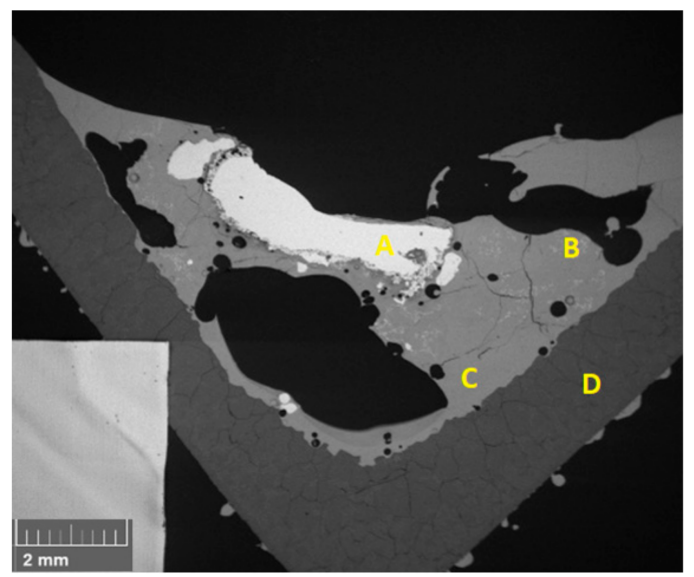

(b) $t=60 \mathrm{~s}$

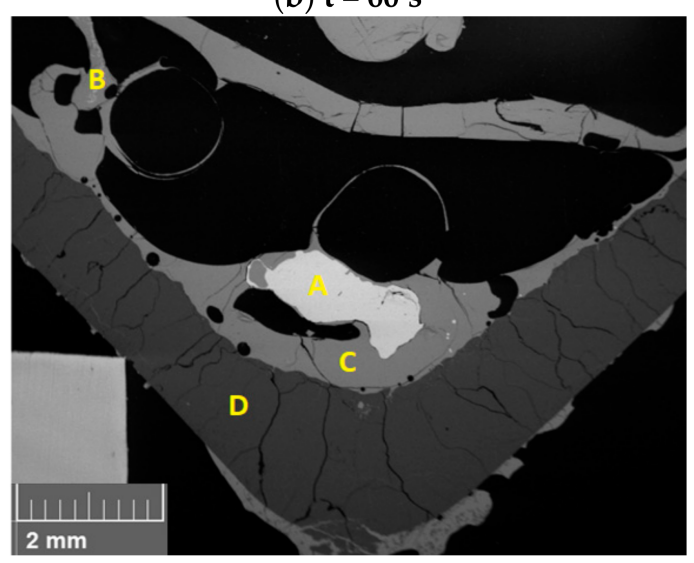

(d) $\mathrm{t}=300 \mathrm{~s}$

Figure 5. SEM-BSE micrographs of the synthetic PCB specimens after different melting times. The letters indicate (a) alloy droplets from PCB, (b) unreacted iron from the slag mixture, (c) liquid slag, and (d) silica crucible. 
Furthermore, pyrolysis of plastics is also a factor in melting behavior. The ceramic fraction dissolved into the slag phase, while the plastic fraction was not found in the EDS analyses. Some black, charred residue was observed in the quenching vessel when opening the gas seal for quenching, which suggests that the plastic fraction was pyrolyzed and exited into the gas phase during the process.

\section{Conclusions}

In this study, the behavior of WPCB and synthetic PCB pieces were examined using silica crucibles that were suspended in a vertical tube furnace. The PCB pieces were dropped on top of a molten slag bath and given time to melt or react for $25,60,120$, and $300 \mathrm{~s}$. After each time interval, the samplecrucible assembly was quenched in ice water, followed by analysis using SEM and EDS.

The most abundant metal in the WPCB scrap was copper, followed by the base metals of lead, tin, and nickel, plus gold and silver as precious metals; all these metals were found in the metal droplets. The metallic fraction of the WPCB formed droplets that tended to settle toward the bottom of the silica crucible due to the density difference between the metals and slag.

The melting time between the WPCB and synthetic PCB were found to be different, mainly due to the ceramic and plastic parts in the WPCB. The ceramic fraction dissolved into the slag phase, and the plastic fraction experienced pyrolysis and formed gases, solid carbon-based compounds, or liquid oils. The additives in the plastic fraction, mainly halogenic fire retardants and possible carcinogenic compounds, may cause both production and safety problems on an industrial scale and, consequently, have to be treated properly.

Based on the observations from the micrographs and EDS analyses, the following conclusions can be drawn:

(1) In this research, 5 min was enough for the samples to completely melt, but the settling process needs more time. In industrial flash-smelting operations, the amount of WPCB scrap feed is much higher and the required melting time needs further investigation and simulation.

(2) WPCB materials can be added into the FS process, and the metal fraction melts readily and forms droplets that settle through the slag layer and mix into the matte phase. However, the ceramic and plastic fractions of WPCB should be removed before; especially the plastic fraction that may cause both production and safety problems. The possible pyrolysis or combustion behavior in the concentrate suspension and slag reduction in the settler also require thorough investigation before larger quantities of WPCB can be safely used as raw material in an industrial-scale process. If not removed in a pretreatment process, the pyrolysis products of the plastic fraction would change the composition of the flue gas, and the recovery and use of flue gas for sulfuric acid production would be influenced by these organic impurities.

(3) The ceramic fraction of the WPCB dissolves into the slag phase after melting, so the slag volume increases if WPCB materials are added in larger amounts.

(4) The precious metals (for example $\mathrm{Au}, \mathrm{Ag}$, and $\mathrm{Pt}$ ) in the WPCB enter the matte phase in the industrial FS process after settling, and they are finally recovered from the anode slime.

Author Contributions: X.W. wrote most of the manuscript and supervised the experiments with L.K.; J.F. performed the experiments, prepared the samples for analysis, and conducted the SEM-EDS analyses with X.W. and L.K.; L.K. and M.M. revised the manuscript; A.J. conceptualized the research idea, supervised the study, helped write the manuscript, and edited and proofread the draft.

Funding: This paper has been supported by TEKES (Business Finland) (CMEco, grant number 7405/31/2016) and by Boliden Harjavalta Oy, and made use of the Academy of Finland's RawMatTERS Finland Infrastructure (RAMI) based at Aalto University. X.W. also received financial support from the China Scholarship Council.

Conflicts of Interest: The authors declare no conflicts of interest. 


\section{References}

1. Radulovic, V. Portrayals in Print: Media Depictions of the Informal Sector's Involvement in Managing E-Waste in India. Sustainability 2018, 10, 966. [CrossRef]

2. Baldé, C.P.; Forti, V.; Gray, V.; Kuehr, R.; Stegmann, P. The Global E-Waste Monitor 2017: Quantities, Flows and Resources; United Nations University: Bonn, Germany; International Telecommunication Union: Geneva, Switzerland; International Solid Waste Association: Vienna, Austria, 2017.

3. Ghosh, B.; Ghosh, M.K.; Parhi, P.; Mukherjee, P.S.; Mishra, B.K. Waste Printed Circuit Boards recycling: An extensive assessment of current status. J. Clean. Prod. 2015, 94, 5-19. [CrossRef]

4. Khaliq, A.; Rhamdhani, M.A.; Brooks, G.; Masood, S. Metal extraction processes for electronic waste and existing industrial routes: A review and Australian perspective. Resources 2014, 3, 152-179. [CrossRef]

5. Reyes-Valderrama, M.I.; Salinas-Rodriguez, E.; Montiel-Hernandez, J.F.; Rivera-Landero, I.; Cerecedo-Saenz, E.; Hernandez-Avila, J.; Arenas-Flores, A. Urban Mining and Electrochemistry: Cyclic Voltammetry Study of Acidic Solutions from Electronic Wastes (Printed Circuit Boards) for Recovery of Cu, Zn, and Ni. Metals 2017, 7, 55. [CrossRef]

6. Zhang, Y.; Liu, S.; Xie, H.; Zeng, X.; Li, J. Current status on leaching precious metals from waste printed circuit boards. Procedia Environ. Sci. 2012, 16, 560-568. [CrossRef]

7. Hagelüken, C. Recycling of electronic scrap at Umicore's integrated metals smelter and refinery. Erzmetall 2006, 59, 152-161.

8. Lennartsson, A.; Engström, F.; Samuelsson, C.; Björkman, B.; Pettersson, J. Large-Scale WEEE Recycling Integrated in an Ore-Based Cu-Extraction System. J. Sustain. Metall. 2018, 4, 222-232. [CrossRef]

9. Ariizumi, M.; Takagi, M.; Inoue, O.; Oguma, N. Integrated processing of e-scrap at Naoshima smelter and refinery. In Proceedings of the Copper 2016, Kobe, Japan, 13-16 November 2016; Volume 6, p. RW 1-2.

10. Wood, J.; Creedy, S.; Matusewicz, R.; Reuter, M. Secondary copper processing using Outotec Ausmelt TSL technology. In Proceedings of the MetPlant 2011, Perth, Australia, 8-9 August 2011; pp. 460-467.

11. Anindya, A. Minor Elements Distribution during the Smelting of WEEE with Copper Scrap. Ph.D. Thesis, School of Civil, Environmental \& Chemical Engineering, RMIT University, Melbourne, Australia, 30 July 2012.

12. Anindya, A.; Swinbourne, D.; Reuter, M.A.; Matusewicz, R. Indium distribution during smelting of WEEE with copper scrap. In Proceedings of the European Metallurgical Conference (EMC 2011), Düsseldorf, Germany, 26-29 June 2011; Volume 1, pp. 3-14.

13. Tran, T.; Wright, S.; Sun, S. Activity of lead in copper matte at very low lead concentration. High Temp. Mater. Process. 2013, 32, 197-206. [CrossRef]

14. Fan, Y.; Gu, Y.; Shi, Q.; Xiao, S.; Jiang, F. Experimental Study on Smelting of Waste Smartphone PCBs Based on $\mathrm{Al}_{2} \mathrm{O}_{3}-\mathrm{FeO}_{\mathrm{x}}-\mathrm{SiO}_{2}$ Slag System. In Proceedings of the 10th International Conference on Molten Slags, Fluxes and Salts, Seattle, WA, USA, 22-25 May 2016; Springer: Cham, Switzerland, 2016; pp. 203-210.

15. Klemettinen, L.; Avarmaa, K.; Taskinen, P.; Jokilaakso, A. Behavior of nickel as a trace element and time-dependent formation of spinels in WEEE smelting. In Proceedings of the Extraction 2018, Ottawa, ON, Canada, 26-29 August 2018; pp. 1073-1082.

16. Avarmaa, K.; O'Brien, H.; Taskinen, P. Equilibria of Gold and Silver between Molten Copper and $\mathrm{FeO}_{\mathrm{x}}-\mathrm{SiO}_{2}-\mathrm{Al}_{2} \mathrm{O}_{3} \mathrm{Slag}$ in WEEE Smelting at $1300{ }^{\circ} \mathrm{C}$. In Proceedings of the 10th International Conference on Molten Slags, Fluxes and Salts, Seattle, WA, USA, 22-25 May 2016; Springer: Cham, Switzerland; pp. $193-202$.

17. Avarmaa, K.; Yliaho, S.; Taskinen, P. Recoveries of rare elements Ga, Ge, In and Sn from waste electric and electronic equipment through secondary copper smelting. Waste Manag. 2018, 71, 400-410. [CrossRef] [PubMed]

18. Klemettinen, L.; Avarmaa, K.; Taskinen, P. Trace Element Distributions in Black Copper Smelting. Erzmetall 2017, 70, 257-264.

19. Avarmaa, K.; Johto, H.; Taskinen, P. Distribution of precious metals (Ag, Au, Pd, Pt, and Rh) between copper matte and iron silicate slag. Metall. Mater. Trans. B 2016, 47, 244-255. [CrossRef]

20. Fan, Y.; Gu, Y. Prediction of the distribution of minor elements in sulfide smelting of waste PCBs. Metal. Int. 2014, 19, 85 .

21. Jorgensen, F.R.A. Single particle combustion of chalcopyrite. Proc. Australas Inst. Min. Metall. 1983, 288, $37-46$. 
22. Chaubal, P.C.; Sohn, H.Y. Intrinsic kinetics of the oxidation of chalcopyrite particles under isothermal and nonisothermal conditions. Metall. Trans. B 1986, 17, 51-60. [CrossRef]

23. Jokilaakso, A.; Suominen, R.; Taskinen, P.; Lilius, K. Oxidation of chalcopyrite in simulated suspension smelting. Trans IMM Sect. C 1991, 100, C79-C90.

24. Jokilaakso, A. Removal of antimony and arsenic from impure copper concentrates under simulated flash smelting reaction shaft conditions. Acta Polytech. Scand. Chem. Technol. Metall. Ser. 1992, 205, 5-55.

25. Peuraniemi, E.; Jokilaakso, A. Reaction sequences in sulphide particle oxidation. In Proceedings of the TMS Annual Meeting 2000, Nashville, TN, USA, 12-16 March 2000; pp. 173-187.

26. Peuraniemi, E.; Järvi, J.; Jokilaakso, A. Behaviour of copper matte particles in suspension oxidation. In Proceedings of the Copper 99, Phoenix, AZ, USA, 10-13 October 1999; pp. 463-476.

27. Perez-Tello, M.; Sohn, H.Y.; St Marie, K.; Jokilaakso, A. Experimental investigation and three-dimensional computational fluid-dynamics modeling of the flash-converting furnace shaft: Part I. Experimental observation of copper converting reactions in terms of converting rate, converting quality, changes in particle size, morphology, and mineralogy. Metall. Mater. Trans. B 2001, 32, 847-868.

28. Guntoro, P.; Jokilaakso, A.; Hellstén, N.; Taskinen, P. Copper Matte-Slag Reaction Sequences and Separation Processes in Matte Smelting. J. Min. Metall. Sect. B Metall. 2018, in press.

29. Kim, Y.H.; Themelis, N.J. Effect of phase transformation and particle fragmentation on the flash reaction of complex metal sulphides. In Proceedings of the Reinhardt Schuhmann International Symposium on Innovative Technology and Reactor Design in Extraction Metallurgy, Warrendale, PA, USA, 9-12 November 1986; pp. 349-369.

30. Ahokainen, T.; Jokilaakso, A. Numerical Simulation of the Outokumpu Flash Smelting Furnace Reaction Shaft. Can. Metall. Q. 1998, 37, 275-283. [CrossRef]

31. Fellman, J. Printed Circuit Board (PCB) Scrap Melting and Mixing with Molten Fayalite Slag. Master's Thesis, School of Chemical Engineering, Aalto University, Espoo, Finland, 10 September 2018.

(C) 2018 by the authors. Licensee MDPI, Basel, Switzerland. This article is an open access article distributed under the terms and conditions of the Creative Commons Attribution (CC BY) license (http://creativecommons.org/licenses/by/4.0/). 